\title{
Management of patients with hip fracture receiving anticoagulation: What are we doing in Canada?
}

\author{
Neil J. White, MD \\ Sarah L. Reitzel, RN, BN \\ Douglas Doyle-Baker, MSc \\ Marlis T. Sabo, MD, MSc \\ Brenna Mattiello, BKin \\ Tina L. Samuel, MBBS
}

Accepted Oct. 28, 2020

\author{
Correspondence to: \\ N. White \\ South Campus Research Unit for Bone \\ and Soft Tissue \\ Division of Orthopaedic Trauma \\ Department of Surgery \\ Cumming School of Medicine \\ University of Calgary \\ 3102654448 Front St SE \\ Calgary AB T3M 1M4 \\ neiljwhite@gmail.com
}

Cite as: Can J Surg 2021 October 1; 64(5). doi: 10.1503/cjs.018520
Background: Direct oral anticoagulants (DOACs) are rapidly replacing warfarin for therapeutic anticoagulation; however, many DOACs are irreversible and may complicate bleeding in emergent situations such as hip fracture. In this setting, there is a lack of clear guidelines for the timing of surgery. The purpose of this study was to evaluate the current practices of Canadian orthopedic surgeons who manage patients with hip fracture receiving anticoagulation.

Methods: In January-March 2018, we administered a purpose-specific cross-sectional survey to all currently practising orthopedic surgeons in Canada who had performed hip fracture surgery in 2017. The survey evaluated approaches to decision-making and timing of surgery in patients with hip fracture receiving anticoagulation.

Results: A total of 280 surgeons representing a mix of academic and community practice, seniority and fellowship training responded. Nearly one-quarter of respondents (66 [23.4\%]) were members of the Canadian Orthopaedic Trauma Society (COTS). Almost three-quarters (206 [73.6\%]) felt that adequate clinical guidelines for patients with hip fracture receiving anticoagulation did not exist, and 177 (61.9\%) indicated that anesthesiology or internal medicine had a greater influence on the timing of surgery than the attending surgeon. A total of 117/273 respondents (42.9\%) indicated that patients taking warfarin should have immediate surgery (with or without reversal), compared to 63/270 $(23.3 \%)$ for patients taking a DOAC $(p<0.001)$. Members of COTS were more likely than nonmembers to advocate for immediate surgery in all patients $(p<0.05)$.

Conclusion: There is wide variability in Canada in the management of patients with hip fracture receiving anticoagulation. Improved multidisciplinary communication, prospectively evaluated treatment guidelines and focus on knowledge translation may add clarity to this issue. Level of evidence: IV.

Contexte : Les anticoagulants oraux directs (AOD) prennent rapidement la place de la warfarine en anticoagulothérapie; or, de nombreux AOD sont irréversibles et peuvent compliquer une hémorragie en cas d'incident comme une fracture de la hanche. Dans ce contexte, il n'y a pas de recommandations claires pour choisir le moment de l'opération. Cette étude avait pour but d'évaluer les pratiques actuelles des chirurgiens orthopédistes canadiens qui traitent des patients avec fracture de la hanche sous anticoagulothérapie.

Méthodes : De janvier à mars 2018, nous avons réalisé un sondage transversal ciblé auprès des chirurgiens orthopédistes en exercice au Canada qui avaient opéré des hanches fracturées en 2017. Ce sondage a servi à évaluer leurs approches concernant la prise de décision et le moment choisi pour opérer les patients avec fracture de la hanche sous anticoagulothérapie.

Résultats : Au total, 280 chirurgiens représentant une multitude de cliniques universitaires et communautaires, de niveaux d'ancienneté et de surspécialités ont participé. Près du quart des répondants (66 [23,4\%]) étaient membres de la Canadian Orthopaedic Trauma Society (COTS). Près des trois quarts (206 [73,6\%]) considéraient qu'il n'y avait pas de directives cliniques adéquates pour les cas de fracture de la hanche sous anticoagulothérapie, et 177 (61,9\%) ont indiqué que l'anesthésie ou la médecine interne avait une plus grande influence que le chirurgien traitant sur le moment choisi pour opérer. Selon 117 répondants sur $273(42,9 \%)$, les patients prenant de la warfarine devraient être opérés sans délai (avec ou sans réversibilité), comparativement à 63 sur 270 (23,3\%) pour les patients prenant des AOD $(p<0,001)$. Les membres de la COTS étaient plus susceptibles que les autres de préconiser une opération immédiate chez tous les patients $(p<0,05)$.

Conclusion : Au Canada, la prise en charge des patients avec fracture de la hanche sous anticoagulothérapie varie considérablement. Le fait d'améliorer la communication transdisciplinaire, d'évaluer prospectivement les directives sur les traitements et de tabler sur l'application des connaissances pourrait clarifier la question. Niveau de preuve : IV. 
W arfarin, a vitamin $\mathrm{K}$ antagonist, was first used in humans in the mid-20th century. It has since become commonly used worldwide for therapeutic anticoagulation of atrial fibrillation, thrombosis and valvular heart disease. ${ }^{1}$ The effectiveness and safety of warfarin depend on close monitoring of a narrow therapeutic window susceptible to multiple food and drug interactions. Falling outside the window means an increased risk of bleeding or reduced medication effectiveness for the target condition. To overcome these specific problems, ${ }^{2}$ direct oral anticoagulants (DOACs) that target factor $\mathrm{Xa}$ and thrombin were developed. ${ }^{3}$ Compared to warfarin, DOACs need less monitoring, have stable drug activity levels and have been shown to be safe in large clinical trials. ${ }^{3}$ There is increased advocacy for use of DOACs for conditions for which warfarin was previously indicated. ${ }^{4}$

However, although DOACs may address the difficulties with warfarin, a large problem still exists: a number of DOACs lack reversal agents for use in emergent settings. ${ }^{5-7}$ Hypocoagulability due to warfarin also poses a grave surgical risk but is managed through the intravenous administration of vitamin $\mathrm{K}$ in combination with fresh frozen plasma or prothrombin complex concentrate or both. Direct oral anticoagulants cannot be managed with these products, which prevents timely and clinically appropriate treatment for patients requiring emergent surgery. ${ }^{8}$ One particularly vulnerable patient group is older patients with hip fracture, in whom surgical delay may be lifethreatening and who will continue to bleed internally regardless of the timing of surgery. ${ }^{9}$

With the aging population, the frequency of hip fractures is expected to increase, and it is becoming obvious that delays to surgery increase morbidity and mortality in these patients. ${ }^{10-12}$ Enthusiastic adoption of DOAC use in older people is creating a barrier to expedient surgery, and there are no high-quality, evidence-based guidelines for management of patients receiving DOACs in the perioperative period. There is also no evidence to suggest that delaying hip fracture repair is beneficial in patients receiving any type of anticoagulation. Because of this, deciding on the timing of surgery is often made through the collaboration of surgery, anesthesiology and internal medicine, and is often based on prior personal experience or institutional habits. Uncertainty and inconsistency of practice in managing use of DOACs may hinder patient access to care, increase overall morbidity and lead to poorer clinical outcomes. ${ }^{13,14}$

The first step in improving care is to understand the current care environment. The purpose of this study was to assess the current opinions, practices and experience of Canadian orthopedic surgeons when presented with a patient with hip fracture receiving warfarin or a DOAC. Our hypothesis was that Canadian surgeons' approach to this situation is highly variable.

\section{Methods}

The proposed study was approved by the University of Calgary Conjoint Health Research Ethics Board (REB17-1785).

\section{Survey design and development}

A purpose-specific cross-sectional survey was developed by 3 of the authors (N.J.W., T.L.S., M.T.S.) at the primary study centre. The intent of the survey was to capture information in 3 domains: surgeon characteristics (demographic characteristics, subspecialty training and clinical practice type); surgeon perception of timing of hip fracture surgery for patients receiving anticoagulants; and surgeon approaches to specific clinical scenarios presented in the survey. The development of the survey questions was guided by the American College of Chest Physicians (CHEST) guidelines, ${ }^{15}$ the Alberta Hip Fracture Care Pathway Tool$\mathrm{kit}^{16}$ and the personal experiences of the research team.

We conducted a pilot study to test the face validity of the survey. Ten practising orthopedic surgeons in Calgary, Alberta were selected for the initial test. After completing the survey, they edited and critiqued the questionnaire to further refine and prepare it for wider dissemination in both English and French. The survey was translated into French by a bilingual coauthor (D.D.-B.). Study data were collected electronically and managed using a research electronic data-capture system (REDCap) hosted at the University of Calgary Clinical Research Unit. REDCap is a secure, Web-based application designed to support data capture for research studies, providing an intuitive interface for validated data entry, audit trails for tracking data manipulation and export procedures, automated export procedures for seamless data downloads to common statistical packages, and procedures for importing data from external sources.

The finalized survey consisted of 4 sections with 16 core questions and optional open-ended questions (Appendix 1, available at canjsurg.ca). Section 1 assessed the current preoperative management of patients with hip fracture receiving anticoagulation at individual institutions. Section 2 presented 2 hypothetical cases of patients receiving anticoagulation; respondents were asked to indicate their preferred management. Section 3 explored the use of tranexamic acid in patients with hip fracture. Section 4 elicited demographic information including the region and type of practice, years in practice, volume of hip fracture procedures performed within a given year and specialty training. No personal identifying information was collected.

\section{Participant recruitment}

All currently practising orthopedic surgeons in Canada who had performed hip fracture surgery in 2017 were 
eligible to participate. Retired surgeons, medical students, residents and fellows in training were ineligible. Orthopedic surgeons were invited to participate through their respective regional and national orthopedic associations, academic institutions, community hospitals and subspecialty groups. Permission was granted by all organizations to distribute the survey to their members using their respective administrative teams and electronic mailing lists. Implied consent was obtained on survey completion. Participants were given 3 months to respond to the survey (Jan. 1-Mar. 31, 2018), and a follow-up reminder email was sent at the midpoint. The survey was voluntary and without incentive.

Quantifying the total number of Canadian orthopedic surgeons who fix hip fractures proved challenging; at best, the number is an estimate based on self-reporting ${ }^{17}$ and personal communications combined with general population metrics. This strategy yielded an estimate of 1162 surgeons performing hip fracture surgery across Canada, which constituted the survey's target population. We used this estimate to calculate a sample size of 289 respondents ( $95 \%$ confidence, $5 \%$ error) to be representative of the entire group.

\section{Statistical analysis}

We compared categorical variables using descriptive statistics, the Pearson $\chi^{2}$ test or the Fisher exact test, as appropriate. All statistical analyses were conducted with SPSS Statistics software, Version 24 (IBM Corp.) in which all tests were 2 -sided and a $p$ value $\leq 0.05$ was considered to be significant.

\section{Results}

A total of 289 responses were collected, of which 280 were complete and usable, for an estimated response rate of $24.1 \%$. Each province was represented. The respondents' demographic characteristics by primary practice location are shown in Table 1. About half (142 [50.7\%]) of surgeons reported practising in a community of fewer than 500000 people (Appendix 2, available at canjsurg.ca). A total of 118 respondents $(42.1 \%)$ reported that they were in the later stages of their career ( $>14 \mathrm{yr})$. Onethird of respondents (94 [33.6\%]) reported having trauma subspecialty training, and almost one-quarter (66 [23.6\%]) were members of the Canadian Orthopaedic Trauma Society (COTS). Community and academic hospitals were equally represented as the primary place of work (Appendix 2). A total of 223/269 surgeons (82.9\%) reported that they had performed 20 or more hip fracture procedures in the previous year. Almost half (138 [49.3\%]) reported anticoagulation in $11 \%-25 \%$ of their patients with hip fracture.

Almost three-quarters of respondents (206 [73.6\%]) felt that adequate clinical guidelines did not exist for the
Table 1. Respondents' demographic characteristics by primary practice location

\begin{tabular}{|c|c|c|c|}
\hline \multirow[b]{2}{*}{ Characteristic } & \multicolumn{3}{|c|}{$\begin{array}{c}\text { Primary practice location; no. (\%) } \\
\text { of respondents }\end{array}$} \\
\hline & $\begin{array}{c}\text { Academic } \\
\text { institution } \\
n=113\end{array}$ & $\begin{array}{l}\text { Community } \\
\text { hospital } \\
n=100\end{array}$ & $\begin{array}{c}\text { All* } \\
n=280\end{array}$ \\
\hline \multicolumn{4}{|l|}{ Level of expertise } \\
\hline Early career $(<7$ yr $)$ & $26(23.0)$ & $31(31.0)$ & 72 (25.7) \\
\hline Mid-career (7-14 yr) & $26(23.0)$ & $29(29.0)$ & $74(26.4)$ \\
\hline Late career (> $14 \mathrm{yr}$ ) & $53(46.9)$ & $37(37.0)$ & $118(42.1)$ \\
\hline Missing & $8(7.1)$ & $3(3.0)$ & $16(5.7)$ \\
\hline \multicolumn{4}{|l|}{ Fellowship training } \\
\hline Orthopedic trauma & $62(54.9)$ & $13(13.0)$ & 94 (33.6) \\
\hline Arthroplasty & $41(36.3)$ & $30(30.0)$ & 94 (33.6) \\
\hline Other & 19 (16.8) & $31(31.0)$ & $70(25.0)$ \\
\hline None & $2(1.8)$ & $31(31.0)$ & $43(15.4)$ \\
\hline COTS member & $54(47.8)$ & $55(55.0)$ & $66(23.6)$ \\
\hline \multicolumn{4}{|c|}{$\begin{array}{l}\text { No. of hip fracture procedures } \\
\text { in } 2017\end{array}$} \\
\hline$<20$ & $20(17.7)$ & $18(18.0)$ & $45(16.1)$ \\
\hline $20-50$ & $61(54.0)$ & $57(57.0)$ & $164(58.6)$ \\
\hline$>50$ & $26(23.0)$ & $23(23.0)$ & $60(21.4)$ \\
\hline Not applicable & $6(5.3)$ & $2(2.0)$ & $11(3.9)$ \\
\hline \multicolumn{4}{|c|}{$\begin{array}{l}\text { Patients with hip fracture who } \\
\text { received anticoagulants in } \\
2017, \%\end{array}$} \\
\hline$<5$ & $5(4.4)$ & $6(6.0)$ & $14(5.0)$ \\
\hline $5-10$ & 39 (34.5) & $24(24.0)$ & 78 (27.9) \\
\hline $11-25$ & 47 (41.6) & $53(53.0)$ & $140(50.0)$ \\
\hline$>25$ & $22(19.5)$ & $17(17.0)$ & $48(17.1)$ \\
\hline
\end{tabular}

management of patients with hip fracture receiving anticoagulation. A total of $177(63.2 \%)$ indicated that the anesthesia or internal medicine teams, or both, had the greatest influence on the timing of surgery for patients with hip fracture receiving anticoagulants.

A total of $117 / 273$ respondents (42.9\%) indicated that they would advocate for expedited surgery when presented with a patient receiving warfarin, compared to $63 / 270$ $(23.3 \%)$ when presented with a patient receiving a DOAC, a statistically significant difference $(p<0.001)$ (Figure 1$)$.

We found no significant difference according to level of expertise in whether surgeons would advocate for immediate versus delayed surgery in either anticoagulation group (Table 2). There was also no significant difference in advocating for immediate versus delayed surgery according to fellowship training. Members of COTS were more likely than nonmembers to advocate for immediate surgery for both patients receiving warfarin $(p<0.001)$ and those receiving a DOAC $(p=0.04)$.

Significantly more respondents reported that they would sometimes, often or almost always use tranexamic acid in patients undergoing elective arthroplasty $(216 / 231$ [93.5\%]) than in those with polytrauma (119/205 [58.0\%]) or hip fracture $(149 / 271[55.0 \%])(p<0.001)$. 


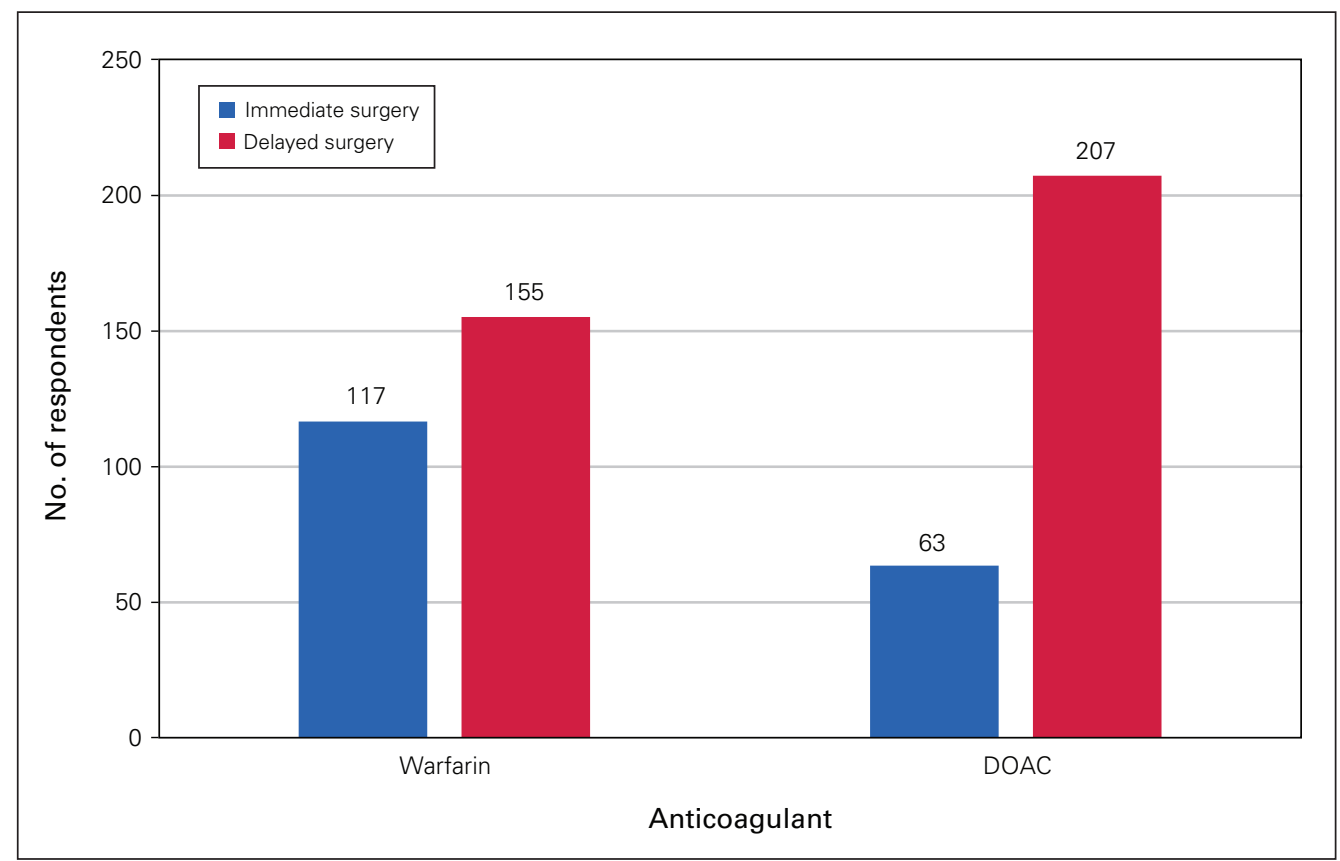

Fig. 1. Number of respondents who would advocate for immediate versus delayed surgery for patients with a hip fracture receiving anticoagulation with warfarin or a direct oral anticoagulant (DOAC) $(p<0.001)$.

\begin{tabular}{|c|c|c|c|c|c|c|}
\hline \multirow[b]{2}{*}{ Characteristic } & \multicolumn{3}{|c|}{ Warfarin; no. (\%) of respondents } & \multicolumn{3}{|c|}{ DOAC; no. $(\%)$ of respondents } \\
\hline & $\begin{array}{l}\text { Immediate } \\
\text { surgery }\end{array}$ & $\begin{array}{l}\text { Delayed } \\
\text { surgery }\end{array}$ & $p$ value & $\begin{array}{l}\text { Immediate } \\
\text { surgery }\end{array}$ & $\begin{array}{l}\text { Delayed } \\
\text { surgery }\end{array}$ & $p$ value \\
\hline Level of expertise & & & 0.1 & & & 0.6 \\
\hline Early career & 38 (52.8) & $34(47.2)$ & & 19 (26.4) & 53 (73.6) & \\
\hline Mid-career & 23 (35.4) & $42(64.6)$ & & $13(17.6)$ & 61 (82.4) & \\
\hline Late career & 59 (46.8) & $67(53.2)$ & & $27(23.1)^{*}$ & $89(76.1)^{*}$ & \\
\hline Fellowship training & & & 0.1 & & & 0.6 \\
\hline Orthopedic trauma & $53(56.4)$ & $41(43.6)$ & & $29(30.8)^{*}$ & $64(68.1)^{*}$ & \\
\hline Arthroplasty & $30(46.9)$ & $34(53.1)$ & & $12(18.8)$ & $52(81.2)$ & \\
\hline Other & $28(40.6)$ & $41(59.4)$ & & $14(20.3)$ & 55 (79.7) & \\
\hline COTS membership & & & $<0.001$ & & & 0.04 \\
\hline Member & $42(63.6)$ & $24(36.4)$ & & $21(31.8)^{*}$ & $44(66.7)^{*}$ & \\
\hline Nonmember & 79 (38.7) & $125(61.3)$ & & 40 (19.6) & $164(80.4)$ & \\
\hline
\end{tabular}

\section{Discussion}

This survey shows the practice variability in 2017 among Canadian orthopedic surgeons in the management of patients with acute hip fracture receiving anticoagulation. Regardless of the type of anticoagulant used, there was a trend toward delaying surgery. Surprisingly, a majority of attending orthopedic surgeons $(61.9 \%)$ did not feel they were the most responsible physician in dictating the timing of surgery. This decision to delay did not seem to be influenced by individual practice factors, such as region, type of practice, years of experience or specialty training. Members of COTS, a research-focused group, were more likely than nonmembers to expedite surgery regardless of type of anticoagulation. This relation should be further explored.

Strong evidence exists that prioritizing hip fracture surgery leads to improved outcomes, decreased mortality and decreased length of hospital stay. ${ }^{10-12}$ There is less evidence regarding patients with hip fracture receiving anticoagulation. Ahmed and colleagues ${ }^{18}$ showed that the use of a protocol for patients taking warfarin decreased time 
to surgery from 73 to 37 hours without increased complications or blood loss. Mullins and colleagues ${ }^{19}$ published a retrospective analysis of 63 consecutive patients with hip fracture receiving a DOAC who underwent expedited surgery (rather than being delayed for drug metabolism) and a matched cohort from the National Hip Fracture Database. The average time from admission to surgery was 19 (range 7-64) hours, with no significant difference in rates of perioperative mortality or transfusion, or decrease in hemoglobin level. A further study of 19 expedited patients receiving DOACs compared to a matched cohort gave similar findings. ${ }^{20}$

Given the lack of robust evidence, practice patterns in the management of patients with hip fracture receiving anticoagulation have not evolved over the years across Canada. ${ }^{8,21}$ National guidelines do not exist. Soft regional, provincial and international guidelines or recommendations do exist; however, to our knowledge, they are not followed regularly and have never been evaluated prospectively.

The issue is complex. One layer of complexity is that medical providers tend to function in practice silos, with the result that collaborative guidelines do not get established at any level. Substantial time can elapse while the various stakeholders (internal medicine, anesthesia, orthopedic surgery and patient/family) debate the "right" decisions. The problems inherent in this silo effect are exacerbated by individual variation in opinion and practice within each silo. The net result is that the best-practice answer changes every day.

A second layer to consider is that, within the silo of orthopedic surgery, knowledge translation is not as effective as it could be. Despite reasonable evidence that patients with hip fracture receiving anticoagulation should not wait for surgery, in our experience, there is still a strong impulse toward delay among surgeons. Intuitively, this delay is reasonable as the surgeon contemplates the patient exsanguinating on the table. Local and national champions could provide a solution by creating logical treatment pathways followed by prospective evaluation and publication.

Tranexamic acid is an antifibrinolytic that has been used to limit bleeding and decrease the need for transfusion in orthopedic procedures. ${ }^{22}$ It has been shown to be effective in elective hip and spine surgery, as well as for use in the polytrauma setting. ${ }^{23-26}$ The World Health Organization has placed this medication on its essential list for patients with trauma. ${ }^{27,28}$ Although the use of tranexamic acid has been studied and advocated in patients with hip fracture, ${ }^{29}$ we saw wide practice variability: onethird of our respondents reporting using tranexamic acid often or almost always in patients with hip fracture, compared to $70.4 \%$ for patients undergoing elective arthroplasty $(p<0.001)$. This again may be a lack of adequate knowledge translation.

\section{Limitations}

With 280 respondents, our study was slightly underpowered (projected representative sample size 289), and therefore our sampled population may not be representative of all Canadian orthopedic surgeons treating hip fractures. In addition, almost one-quarter of respondents were COTS members; thus, this group may not be representative of the "typical" Canadian surgeon. We assessed self-reported perceptions, and self-assessment usually leads to substantial recall bias. ${ }^{30}$ The survey design also had limitations. The questions were not randomized or alternated, and we did not use cookies or individual IP addresses to track respondents. As such, view rate, participation rate and completion rate were not calculated. The survey did not give respondents an opportunity to review or edit their answers, which may have affected the accuracy of their responses.

\section{Conclusion}

The lack of consensus and of established guidelines on the management of patients with hip fracture receiving DOACs highlights the need for well-designed randomized controlled trials to rigeriously establish best-practice pathways for the fragile patient population. The results could aid to diminish variability of care and improve patient outcomes.

Acknowledgements: The authors thank the SCRUBS (South Campus Research Unit for Bone and Soft Tissue) team, Dr. Marcia Clark, Martina Vergouwen and Brendan Kelliher for their assistance and support in survey design and validation. They also thank Drs. Daniel Pincus and Hans J. Kreder, Department of Surgery, University of Toronto, for their personal communications and assistance in estimating the total number of Canadian orthopedic surgeons, and the Canadian Orthopaedic Trauma Society for assistance with participant recruitment.

Affiliations: From the Division of Orthopaedic Trauma, Department of Surgery, Cumming School of Medicine, University of Calgary, Calgary, Alta. (White, Reitzel, Doyle-Baker, Sabo, Samuel); the McCaig Institute of Bone and Joint Health, Calgary, Alta. (White, Sabo); and the South Campus Research Unit for Bone and Soft Tissue, University of Calgary, Calgary, Alta. (Mattiello).

Competing interests: Neil White consults for Bioventus and ConMed and has received research support from Bioventus, Arthrex and Acumed outside the submitted work. No other competing interests were declared.

Contributors: N. White, M. Sabo and T. Samuel designed the study. N. White, D. Doyle-Baker and T. Samuel acquired the data, which N. White, S. Reitzel, D. Doyle-Baker, B. Mattiello and T. Samuel analyzed. N. White, S. Reitzel, D. Doyle-Baker and T. Samuel wrote the manuscript, which S. Reitzel, D. Doyle-Baker, M. Sabo, B. Mattiello and T. Samuel critically revised. All authors gave final approval of the article to be published.

Content licence: This is an Open Access article distributed in accordance with the terms of the Creative Commons Attribution (CC BYNC-ND 4.0) licence, which permits use, distribution and reproduction in any medium, provided that the original publication is properly cited, the use is noncommercial (i.e., research or educational use), and no modifications or adaptations are made. See: https://creativecommons. org/licenses/by-nc-nd/4.0/. 
Funding: This study was supported financially through the Section of Orthopaedics, University of Calgary, and donations to the SCRUBS (South Campus Research Unit for Bone and Soft Tissue) program, University of Calgary.

\section{References}

1. Pirmohamed M. Warfarin: almost 60 years old and still causing problems. Br 7 Clin Pharmacol 2006;62:509-11.

2. Loo SY, Dell'Aniello S, Huiart L, et al. Trends in the prescription of novel oral anticoagulants in UK primary care. Br 7 Clin Pharmacol 2017;83:2096-106.

3. Enriquez A, Lip GYH, Baranchuk A. Anticoagulation reversal in the era of the non-vitamin K oral anticoagulants. Europace 2016;18: 955-64.

4. Weitz JI, Semchuk W, Turpie AGG, et al. Trends in prescribing oral anticoagulants in Canada, 2008-2014. Clin Ther 2015;37:250614.e4.

5. Granger CB, Alexander JH, McMurray JJV, et al. Apixaban versus warfarin in patients with atrial fibrillation. NEngl f Med 2011;365: 981-92.

6. Connolly SJ, Ezekowitz M. Dabigatran versus warfarin in patients with atrial fibrillation. N Engl f Med 2009;361:1139-51.

7. Patel MR, Mahaffey KW, Garg J, et al. Rivaroxaban versus warfarin in nonvalvular atrial fibrillation. N Engl F Med 2011;365:883-91.

8. Sabo MT, Mahdi F, Clark M. Emerging barrier to timely care of hip fracture patients: a prospective study of direct oral anticoagulation and time to surgery. Can 7 Gen Intern Med 2018;13:e6-9.

9. Cohn MR, Levack AE, Trivedi NN, et al. The hip fracture patient on warfarin: evaluating blood loss and time to surgery. 7 Orthop Trauma 2017;31:407-13.

10. Zuckerman JD, Skovron ML, Koval KJ, et al. Postoperative complications and mortality associated with operative delay in older patients who have a fracture of the hip. 7 Bone foint Surg Am 1995;77:1551-6.

11. Al-Ani AN, Samuelsson B, Tidermark J, et al. Early operation on patients with a hip fracture improved the ability to return to independent living: a prospective study of 850 patients. 7 Bone foint Surg Am 2008;90:1436-42.

12. Solomon CG, Bhandari M, Swiontkowski M. Management of acute hip fracture. N Engl 7 Med 2017;377:2053-62.

13. Kanis JA, Odén A, McCloskey EV, et al. A systematic review of hip fracture incidence and probability of fracture worldwide. Osteoporos Int 2012;23:2239-56.

14. Tarride JE, Hopkins RB, Leslie WD, et al. The burden of illness of osteoporosis in Canada. Osteoporos Int 2012;23:2591-600.

15. Guidelines and topic collections. Glenview (IL): American College of Chest Physicians. Available: https://www.chestnet.org/Guidelines -and-Topic-Collections (accessed 2017 Sept. 15).
16. Hip Fracture Care Pathway Toolkit. Edmonton: Alberta Health Services; 2017, updated 2021. Available: https://www.albertahealthservices. $\mathrm{ca} / \mathrm{scns} / \mathrm{hfcptoolkit.aspx}$ (accessed 2017 Sept 15).

17. Orthopedic surgery profile. Ottawa: Canadian Medical Association; 2018, updated 2019 December. Available: https://www.cma.ca/ sites/default/files/2019-01/orthopedic-surgery-e.pdf (accessed 2021 Aug. 27).

18. Ahmed I, Khan MA, Nayak V, et al. An evidence-based warfarin management protocol reduces surgical delay in hip fracture patients. 7 Orthop Traumatol 2014;15:21-7.

19. Mullins B, Akehurst H, Slattery D, et al. Should surgery be delayed in patients taking direct oral anticoagulants who suffer a hip fracture? A retrospective, case-controlled observational study at a UK major trauma centre. BMF Open 2018;8:e020625.

20. Franklin NA, Ali AH, Hurley RK, et al. Outcomes of early surgical intervention in geriatric proximal femur fractures among patients receiving direct oral anticoagulation. 7 Orthop Trauma 2018;32: 269-73.

21. Massicotte A. A practice tool for the new oral anticoagulants. Can Pharm 7 2013;147:25-32.

22. Zufferey P, Merquiol F, Laporte S, et al. Do antifibrinolytics reduce allogeneic blood transfusion in orthopedic surgery? Anesthesiology 2006;105:1034-46.

23. CRASH-2 Collaborators; Roberts I, Shakur H, Afolabi A, et al. The importance of early treatment with tranexamic acid in bleeding trauma patients: an exploratory analysis of the CRASH-2 randomised controlled trial. Lancet 2011;377:1096-101, 1101.e1-2.

24. Kagoma YK, Crowther MA, Douketis J, et al. Use of antifibrinolytic therapy to reduce transfusion in patients undergoing orthopedic surgery: a systematic review of randomized trials. Thromb Res 2009;123: 687-96.

25. Eubanks JD. Antifibrinolytics in major orthopaedic surgery. $7 \mathrm{Am}$ Acad Orthop Surg 2010;18:132-8.

26. Yuan C, Zhang H, He S. Efficacy and safety of using antifibrinolytic agents in spine surgery: a meta-analysis. PLoS One 2013;8:e82063.

27. Roberts I. Tranexamic acid - a recipe for saving lives in traumatic bleeding. East Mediterr Health f 2011;17:638.

28. Ker K, Kiriya J, Perel P, et al. Avoidable mortality from giving tranexamic acid to bleeding trauma patients: an estimation based on WHO mortality data, a systematic literature review and data from the CRASH-2 trial. BMC Emerg Med 2012;12:3.

29. Sadeghi M, Mehr-Aein A. Does a single bolus dose of tranexamic acid reduce blood loss and transfusion requirements during hip fracture surgery? A prospective randomized double blind study in 67 patients. Acta Med Iran 2007;45:437-42.

30. Raphael K. Recall bias: a proposal for assessment and control. Int $\mathcal{f}$ Epidemiol 1987;16:167-70. 